\title{
PLATÓN, ATRAPADO BAJO EL PESO DE LA NEGACIÓN ABSOLUTA DE PARMÉNIDES
}

\section{NÉSTOR LUIS CORDERO}

Profesor emérito Universidad de Rennes 1, Francia

nestor.luis.cordero@gmail.com

Recibido: 26/05/20

Aceptado: 25/08/20

Parménides había escrito que "hay [ser] y no es posible no ser" (fr. 2. 3) y, en consecuencia, "es necesario existir absolutamente, o no" (fr. 8. 11). El carácter absoluto de esta tesis excluye toda posibilidad de que algo que no es, sea, puesto que "nunca se impondrá esto: que haya cosas que no son" (fr. 7. 1). Pero ocurre que el diálogo, fundamento de la filosofía, supone opiniones enfrentadas, incluso contradictorias, y, según la interpretación de Parménides que se tiene en la época de Platón, y que él comparte, toda negación supone contrariedad, y si una tesis dice las cosas tal como son, su contradictoria diría "lo que no es". El objetivo principal del Sofista es, precisamente, justificar la posibilidad del discurso falso, a pesar de que diga "lo que no es". Y para ello debe relativizar la noción de no-ser absoluto de Parménides y transformarlo en "no ser lo mismo que... X", o sea, "ser diferente de...": un discurso falso dice algo "diferente" de lo que es. Pero este no-ser en tanto que diferente sólo tiene vigencia predicativa. Ontológicamente, el no-ser absoluto no existe, y Platón admite implícitamente que Parménides no estaba equivocado.

\section{Platón / Parménides / No-ser / Contrariedad / Otredad}

\section{PLATO, TRAPPED BY THE WEIGHT OF THE ABSOLUTE NEGATION OF PARMENIDES}

Parmenides had written that "there is [to be] and it is not possible not to be" (fr. 2. 3) and, consequently, that "it is necessary to exist absolutely, or not" (Fr. 8. 11). The absolute nature of this thesis excludes any possibility for being of something that is not, because since "this will never be imposed: that there are things that are not" (fr. 7. 1). But "dialogue", the foundation of philosophy, implies opposing opinions, even contradictory, and, according to Parmenides' interpretation in Plato's time (interpretation that he shares), every denial implies contradiction, and if a discourse that expose things as they are, a contradictory discourse would say "what is not". The main objective of the Sophist 
is precisely to justify the possibility of false discourse, even if it says "what is not". And to do so Plato must relativize the notion of Parmenides' absolute not-being and transform it into "not to be the same as... X", that is, "to be different from...": a false speech says something "different" from what it is. But this not-being as different has only predicative validity. Ontologically, the absolute not-being does not exist, and Plato implicitly admits that Parmenides was not wrong.

\section{Plato / Parmenides / Not-being / Contrarity / Otherness}

Cuando Platón tiene un poco más de sesenta años -y sin haber leído a Freud-, decide desembarazarse de la figura de su padre espiritual. En su caso no se trata, como en Edipo, de eliminar a un desconocido, que resultó ser su propio padre. Platón es consciente de que, para que no sólo su filosofía sino LA filosofía pueda seguir avanzando, es necesario suprimir a Parménides, como él dice en el Sofista, es decir, hay que superar la tesis paterna, según la cual el hecho de ser es necesario y absoluto. En efecto, Parménides había escrito que "hay [ser] y no es posible no ser" (fr. 2. 3) y, en consecuencia, "es necesario existir absolutamente, o no" (fr. 8. 11). El carácter absoluto de esta tesis excluye toda posibilidad de que algo que no es, sea, puesto que "nunca se impondrá esto: que haya cosas que no son" (fr. 7. 1). Pero ocurre que el diálogo, fundamento de la filosofía, supone opiniones enfrentadas, incluso contradictorias, y, según la interpretación de Parménides que se tiene en la época de Platón, y que él comparte, toda negación supone contrariedad y, si una tesis dice las cosas tal como son, su contradictoria diría "lo que no es".

La tarea que Platón se propone es titánica y sería ilusorio pretender seguirla paso a paso en los estrechos límites de este trabajo, pero, como en una mala novela policial, me permito contar desde ya el final de la historia: como consecuencia de su crítica a Parménides, Platón aportará novedades que van a cambiar el curso de la filosofía, en especial, en lo que concierne al lógos como discurso. Pero Platón deberá pagar un precio muy elevado por la innovación que introducirá en el ámbito del lógos, pues quedará sepultado bajo el peso abrumador de la negación absoluta, que es la otra cara de la medalla del ser absoluto de Parménides. La negación como "diferencia", que es la novedad que Platón propondrá, será válida, en el Sofista, para el ámbito del discurso, si bien tendrá como respaldo una de las Formas "mayores", la de Lo Otro. Va de suyo que Platón no refuta que, ontológicamente, como había sostenido Parménides, "no hay algo que no sea".

Vayamos por partes y veamos, en primer lugar, la posición de Parménides, una vez más, en forma más que somera.

Como es sabido, sólo quedan citas del Poema de Parménides (mal llamadas "fragmentos": una cita supone un citador; un fragmento es el trozo auténtico de algo), que desde hace más de dos siglos (la última cita fue encontrada recién en 1810) se agruparon, al menos la mayor parte de ellas, de manera totalmente arbitraria (sólo cuatro 
o cinco citas de las diecinueve recuperadas deben ubicarse forzosamente antes o después de algunas otras). Entre éstas, el texto conocido hoy como "fragmento 1" corresponde, sin lugar a dudas, al inicio del Poema, ya que Sexto Empírico, el único citador de los primeros treinta versos, aclara, antes de citarlos: "Así comenzaba el Perì Phúseós de Parménides" (M. VII. 111).

En esta suerte de introducción al Poema, conocida como Proemio, Parménides ofrece una alegoría de la investigación filosófica: un estudiante, acompañado por las hijas del Sol y empujado por su entusiasmo (o "ánimo", o "voluntad", thumós), emprende un viaje desde el reino de la noche (=la ignorancia) hacia el dominio luminoso de la verdad, donde es acogido por una auténtica "maestra de filosofía", una diosa anónima, alter ego de Parménides. Es la diosa la que dictará, en primera persona, una auténtica lección, que comienza con una exhortación: "Es necesario que estés al tanto de todo, tanto del corazón imperturbable de la verdad bien redondeada, como de las opiniones de los mortales, en las cuales no hay verdadera confianza" (fr. 1. 28b-30). La cita de Parménides que conocemos hoy como primer fragmento ${ }^{1}$ termina con la presentación de esta suerte de programa de estudios.

Como ya dijimos, no sabremos jamás en qué orden deben leerse las citas recuperadas del Poema de Parménides. Sea como fuere, hay otra cita, encontrada tanto en Proclo (Comentario al Timeo de Platón) como en Simplicio (Comentario a la Física de Aristóteles), que parece retomar y explicitar las dos nociones (verdad y opinión) al final del fragmento 1. En este texto, conocido hoy como fragmento 2, la Diosa expone el núcleo de la filosofía de Parménides. Para comprender mejor este dificilísimo pasaje, una breve introducción se impone.

Los filósofos anteriores a Parménides habían consagrado sus esfuerzos a encontrar o descubrir el principio o elemento fundamental de la realidad, de la phúsis, en el sentido de pánta tà ónta. Esta búsqueda suponía que la realidad existía y que había que descifrar sus principios, el elemento básico, su "sustancia". Parménides, sin pronunciarse sobre este cuestionamiento, se coloca en un plano previo. Antes de estudiar qué son las cosas, hay que admitir que hay cosas y, si hay cosas, es porque hay ser. La afirmación parece banal, pero es el verdadero punto de partida del filosofar. Esta verdadera tesis es utilizada por Parménides como un axioma; y un axioma no se demuestra: se postula. Y Parménides dedicó su Poema a analizar el hecho de ser, sus propiedades y, especialmente, su necesidad -y entramos de lleno en nuestro tema- porque es imposible no ser. Esto es lo que dice la Diosa en el fragmento 2, y lo dice mediante una alternativa. Ya en el fr. 1 había sostenido que había que estar al tanto de la verdad y de las opiniones. En este fr. 2 desarrolla ambas posibilidades, y las juzga.

La alternativa es la siguiente: hay dos caminos que permiten, a priori, encaminar el pensamiento $^{2}$ o, si se prefiere, hay dos maneras de investigar. La primera consiste en afirmar que "es" (ésti: no hay sujeto; el sujeto vendrá después) (o que "hay") y que "no es posible (ouk ésti) no ser (mè eînai)". Es éste el camino que persuade y que acompaña a la verdad, ergo, es una de las posibilidades enunciadas ya en el fr. 1.

El otro camino o posibilidad dice exactamente lo contrario. Dice que "no es" (ouk ésti) (o que "no hay") y que "es necesario no ser (khreón esti mè eînai)". Este camino no conduce a ninguna parte, está vacío de contenido, es panapeuthéa. Una simple lectura 
tanto de las tesis expuestas en 2. 3 y en 2. 5 como de la valoración que Parménides les otorga muestra que ambas posibilidades son opuestas.

De lo dicho se ve claramente que Parménides no propone elegir entre A o B como vías de investigación capaces de "encaminar" el pensamiento, como suele decirse, sino entre A y no-A. Si la elección hubiese sido entre dos tesis, por ejemplo, A o B, habría que estar al tanto de ambas tesis. Por ejemplo, cuando el Extranjero del Sofista divide a los filósofos anteriores en "somatistas" e "idealistas", explica a Teeteto en qué consiste cada posición y, si se debe elegir, no se puede afirmar que una posición sea la original y la otra una tesis derivada: ambas son originales.

Para comprender por qué la elección que propone Parménides es entre A y no-A (y no entre $\mathrm{A}$ y B), es necesario violentar la lógica parmenídea y adelantar el sujeto de los versos 2. 3 y 2. 5, que aparecerá claramente en $6.1^{3}$, y que está ausente del fr. 2 . En realidad, basta observar la segunda parte de cada fórmula para deducir desde ya que el sujeto es "ser", un infinitivo.

Me explico: la segunda parte de la primera fórmula dice "no es posible no ser", lo cual supone que "es posible ser", o sea que sin lugar a duda la primera parte, ahora con sujeto, es "[ser] es", o "hay [ser]", o "es posible [ser]", como dirá luego en el verso 2 del fr. 6: "es posible ser (ésti gàr eînai) y la nada no existe". Y otro tanto ocurre con la segunda formulación: "[ser] no es", "no hay [ser]".

Obsérvese que en las dos fórmulas del fragmento 2 el verbo "ser" está ya sea en infinitivo (eînai, con o sin mè), ya sea en la tercera persona, "es" (ésti). El participio tò eón, afirmado o negado, está ausente de estas fórmulas. Nada dice Parménides sobre "El Ser" y sobre "El No-Ser", infinitivos sustantivados, o sea que cualquier semejanza entre la vulgata "el ser es y el no ser no es" y Parménides, es pura coincidencia.

Dado este esquema, uno de los caminos es la negación del otro. Pero la negación es contradictoria. Y en función de este matiz de la negación, la contradictoriedad, la tesis negativa se elimina como autocontradictoria. ¿Por qué autocontradictoria? Porque toda negación supone aquello que niega, en el caso de Parménides, el hecho de ser. Me explico.

Llegamos al centro de nuestro tema: el peso abrumador de la negación contradictoria en una lógica binaria, como la de Parménides. Ocurre que la afirmación y la negación no se encuentran en el mismo nivel ${ }^{4}$ : la negación es secundaria respecto de la afirmación. Obsérvese que cuando Parménides enunció tanto la tesis como la negación, sólo demostró, a su manera, la imposibilidad de la negación. Este segundo camino es un callejón sin salida "porque tú no podrás ni conocer ni mencionar algo que no exista" (fr. 2. 6-7). De la primera tesis, en cambio, no hay demostración: es un axioma. Ahora bien: ¿por qué la afirmación y la negación no se encuentran en el mismo nivel? Porque no se puede negar algo sin tener una idea de aquello que se niega. Si un ateo niega la existencia de dios es porque sabe que hay algo que se llama "dios" y dice: eso no existe.

Pero esto no fue siempre así. HeGEL había puesto en el mismo nivel precisamente al ser y la nada y, cuando en El ser y la nada SARTRE lo critica, dice "le néant est logiquement postérieur à l'être, puisqu'il suppose l'être pour le nier" ${ }^{5}$. Varios años antes, en 1901, el filósofo danés Harald HöffDiNg había escrito en la Révue Philosophique: "le jugement

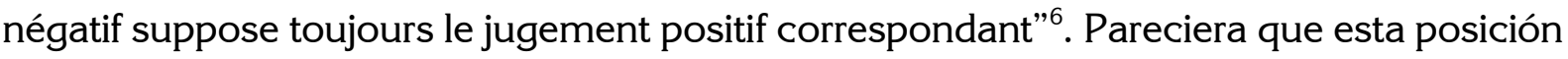


era habitual entre los lógicos del siglo XIX, ya que ella se encuentra en dos autores de la época, KRUG y SIGWART. En efecto, Wilhelm T. KRUG había escrito en 1806 que ninguna negación es concebible sin la concepción concomitante de una afirmación, pues no podemos negar la existencia de algo sin tener una noción de lo que negamos ${ }^{7}$. Y el lógico alemán Christoph VON SIGWART había escrito en 1873 que el objeto de la negación es siempre un juicio ya formulado ${ }^{8}$. Finalmente, en su Tractatus, en el parágrafo 4.0621, L. WITTGENSTEIN sostendrá que el signo '-', que simboliza la negación, no corresponde a nada en la realidad.

Pero quien mejor expuso esta posición fue H. BERGSON. En L'évolution créatrice escribió:

par cela que je dit 'l'objet A' [En el caso de Parménides, el objeto A sería el hecho de ser] je lui attribue une espèce d'existence [...] En conséquence, penser l'objet $A$ inexistant [En el caso de Parménides sería la expresión "no ser"], c'est penser l'objet d'abord et, par conséquent, le penser existant ${ }^{9}$.

Es interesante observar cómo el enemigo más despiadado de Parménides, Gorgias, captó a la perfección el contenido de este segundo camino. Cuando en su tratado sobre el no-ser analiza precisamente el caso del "no-ser", escribe: "Si el no-ser existe, existirá, y, al mismo tiempo, no existirá, pues, en tanto pensamos que no existe, no existe, pero en tanto él es no-ser, existirá" (fr. 3, § 67 = S.E, M. VII, 64).

En Parménides, cuando se piensa al hecho de ser tal como es, no es posible negarlo después, porque la noción de ser, para Parménides, tiene carácter necesario y absoluto (cf. 8. 11: "es necesario ser absolutamente, o no"). Una negación contradictoria es posible en otros casos (por ejemplo, si existen entidades blancas, ello no excluye que existan también no-blancas). Pero en el caso del hecho de ser, ello es imposible, dado el carácter absoluto y necesario del hecho de ser, y por eso, dado lo que es el hecho de ser, no existir es imposible.

Como para negar la existencia del hecho de ser previamente hay que pensarlo (recuérdese el fr. 3: "es lo mismo pensar y ser"), quien pretende negar al hecho de ser ya lo ha pensado con sus atributos de necesario y de absoluto. Decir que el hecho de ser no existe equivale a decir que no existe lo que existe. Esta manera errónea de pensar es incapaz de captar qué es "ser" y qué es "no ser". Para Parménides, quienes trataron de explicar la realidad antes que él (a los que llama "mortales") cometieron este error: "ellos creen que ser y no ser son lo mismo y no lo mismo" (fr. 6. 8-9).

Para Parménides el hecho de ser es necesario y absoluto pues es el fundamento de la realidad; todo lo que existe "posee" ser y este hecho de ser no puede ser aleatorio, provisorio, cambiante. Parménides dice en dos ocasiones que es imposible separar a lo que es del hecho de ser (fr. 4. 2, 8. 25), que es el fundamento de la realidad. Sin querer hacer de Parménides el primer "filósofo del lenguaje", no caben dudas de que (a) la lengua griega lo confirma y de que (b) él supo extraer el trasfondo ontológico que supone la lengua griega. Cuando los primeros filósofos encaran los nuevos objetos de estudio a los que van a consagrarse, los llaman tà ónta (fórmula que figura ya en Anaximandro), o pánta tà ónta, o, directamente, phúsis, como afirma repetidamente Aristóteles. Pero 
ocurre que tà ónta, "los entes", es el participio presente del verbo "ser", en plural. En todas las lenguas, el participio supone un infinitivo; sin el verbo "ser" no habría el participio presente ónta. Parménides extrae o descubre el trasfondo ontológico de este simple "hecho de lengua" ${ }^{10}$ : si no hubiese ser (ya sin comillas), no habría entes. Por consiguiente, la expresión tò mè ón, "lo que no es", es ya, de por sí, autocontradictoria: niega el verbo del cual depende. Francis M. CORNFORD escribió que las palabras 'lo inexistente' (la absoluta no-entidad) no pueden ser pronunciadas de ningún modo sin incurrir en contradicción consigo mismo ${ }^{11}$.

La extensa cita de Parménides conocida como "fragmento 8", encontrada en Simplicio (y, fragmentariamente, en gran cantidad de comentadores), enumera los atributos o propiedades que se derivan del carácter absoluto y necesario del hecho de ser. Todo razonamiento $-\mathrm{y}$, luego, todo discurso- que pretenda descifrar la realidad de los entes debe partir de la admisión necesaria del hecho de ser. El verso 34 del fr. 8 lo dice claramente: "sin el ser, gracias al cual ${ }^{12}$ (eph' hôi $)$ está expresado, no encontrarás el pensar". Ser, pensamiento y discurso van juntos. El discurso, que reconocerá en la realidad los caracteres del hecho de ser, será un lógos verdadero; en caso contrario, será sólo una opinión (dóxa) subjetiva.

Llegados a este punto, debemos ocuparnos del puente que une cuanto hemos visto sobre Parménides, y Platón. Aunque cueste percibirlo, el puente se encuentra en la última frase que hemos escrito. Se trata de la necesidad, para que un lógos sea verdadero, de exponer la realidad tal como es, o, si se prefiere, el ser de las cosas. Recordemos que Platón quiere superar (en realidad, "eliminar") a Parménides para poder justificar la posibilidad de la existencia de un lógos pseudés (falso, mentiroso, erróneo). Y acabamos de ver que para Parménides un lógos es verdadero cuando expone el ser de las cosas. ¿Supone entonces Parménides que un lógos falso tendría como contenido algo que no es? Si es así, no habría ningún lógos falso, ya que lo que no es, no existe, y ningún lógos podría enunciarlo. En realidad, Parménides no dice directamente que el lógos verdadero sólo enuncia el ser de las cosas, pero sin duda hubo autores que lo dedujeron, especialmente Antístenes, como veremos más adelante.

Literalmente, los versos 50 y 51 a del fr. 8 dicen: "Acá termino para ti el lógos confiable (o "fidedigno", pistón) y el pensamiento / acerca de la verdad". Pero ocurre que tanto el discurso como el pensamiento presentaron hasta "acá" las propiedades del hecho de ser, entre ellas, su necesidad, unicidad, inalterabilidad, etc. Y además ya en el fr. 2 Parménides había afirmado que el camino que sostenía que "hay [ser] y no es posible no ser" (2. 3) estaba "acompañado por la verdad", que es una forma elíptica de decir que era verdadero. A partir de estos datos hay autores que dedujeron que, si hay algún discurso que no sea acerca del ser, no podrá ser verdadero.

Uno de los primeros seguidores de Sócrates (mucho antes que Platón), Antístenes, presentó esta tesis en una suerte de silogismo: "Todo lógos dice la verdad, pues, quien dice, dice una cosa ( $t i)$ y quien dice una cosa dice algo que es; ergo quien dice lo que es, dice la verdad" (citado por Proclo, Comentario al Crátilo, 37). Esta tesis se refuerza con su definición del lógos: "el lógos es exhibidor (dêlôn) de lo que era o de lo que es [algo]" (citado por Diógenes Laercio, VI. 3). 
La tesis parece paradojal, pero nadie la refutó hasta Platón, y recién en un diálogo más bien tardío, el Sofista, cuando vio la necesidad de relativizar el ser absoluto y necesario de Parménides para reivindicar la posibilidad de un discurso pseudés, instrumento de trabajo del sofista. Pero, antes de comenzar su crítica, admitió que será "extremadamente difícil" (pantápasi khalepêei) demostrar que "se puede decir algo, sin que eso sea verdadero" (236 d9, e2). Para fundamentar su definición según la cual el sofista es un fabricante de ilusiones, de falsedades y de mentiras, Platón debe justificar la existencia de dichas nociones, que se resumen en dos verbos: phaínesthai y dokeîn ${ }^{13}$ (236 e1). ¿Por qué? Porque estas nociones suponen algo diferente del ser (una ilusión es una apariencia diferente de lo que es) y mentir es decir lo que no es. Es a partir de la justificación de esta posibilidad, negada por Antístenes, que comienza la cuenta regresiva de la refutación de Parménides... pero también de la trampa en la que caerá Platón.

La dificultad de admitir un discurso falso se debe a que este tendría como contenido algo que no es. La tarea titánica de Platón en el Sofista consistirá en descubrir un tipo de no ser capaz de cohabitar con el ser y entonces "ir más allá de los límites que Parménides nos había prohibido franquear" (258 a). Hemos utilizado el verbo "descubrir" porque en el Sofista Platón aprovecha el cambio de portavoz (no es Sócrates, sino un extranjero que viene de Elea, verdadera Ontópolis) para cambiar también su método. A diferencia de diálogos anteriores en los cuales casi siempre Sócrates propone ideas y éstas se discuten (se aprueban o se rechazan), en el Sofista Platón descubre un nuevo tipo de no-ser como resultado de una sistematización que él lleva a cabo de las respuestas de los filósofos anteriores.

Una suerte de historia de la filosofía que llega hasta su diálogo inmediatamente anterior, el Teeteto (ya que Platón va a hablar de sí mismo) le permite a Platón agrupar las escuelas en dos grandes grupos: hubo filósofos que asimilaron la realidad (ousía: 246 a5) a principios corpóreos, ergo, cambiantes, dinámicos, mientras que otros -entre los cuales se encuentra él mismo- sostuvieron que la "realidad real" residía (hasta "ayer") en Formas inteligibles e inalterables. La originalidad de la posición del Extranjero consiste en no privilegiar una respuesta en desmedro de la otra. Al contrario: dice que, como los chicos, cuando deben elegir entre dos cosas, quieren las dos. El filósofo, como los $\operatorname{chicos}^{14}$, debe admitir la realidad real de dos tipos de ousía (como, de hecho, ocurre ya en la filosofía de Platón, si bien, hasta el Sofista, lo individual sensible tiene sólo una existencia relativa al modelo, la Forma; en este diálogo lo justificará).

Pero ces posible sostener la existencia de dos realidades diferentes, más aún, opuestas? Sí, pero con una condición: ninguna de las dos debe monopolizar el hecho de ser, ya que, en ese caso, la otra no existiría. Si un materialista asimila el hecho de ser al cuerpo, niega la existencia de todo lo incorpóreo, y viceversa. La solución que propone Platón la extrae de la existencia real de ambas posiciones entre los filósofos anteriores, él incluido: hay que separar el hecho de ser de los principios, de la ousía, y considerarlo como algo "tercero", término que Platón utiliza en tres ocasiones (243 e2, 250 b7, 250 c1). Es este el "descubrimiento" mayor del Sofista: la ousía sensible y la ousía inteligible existen porque participan del hecho de ser, que, en el Sofista, en función de la noción de "participación" que Platón no abandona, supone una Forma que está "presente" en 
aquello que participa de ella: la Forma de Ser (Idéa toû óntos, 254 a8). Esta nueva Forma deberá ser supuesta por todas las otras (ya que todas necesitan participar de ella).

La Forma de Ser permite justificar la coexistencia simultánea de los opuestos, y es en función de esta cohabitación que Platón "descubre", una vez más, qué se entiende por negación, que es nuestro tema. La explicación tradicional (¿parmenídea?) según la cual la negación es lo contrario de la afirmación no se adapta al hallazgo mayor del Sofista: la coexistencia de los contrarios. En uno de los pasajes más citados del diálogo, el Extranjero concluye (257b-c):

No estemos de acuerdo, entonces, cuando se diga que la negación significa lo contrario, y admitamos sólo que el 'no' colocado antes hace alusión a algo diferente (ti tôn allônn) de los nombres que siguen, o más aún, de los hechos respecto de los cuales se colocan los nombres pronunciados después de la negación.

Acorde con esta interpretación, "según parece, cuando hablamos de lo que no es, no hablamos de algo contrario a lo que es, sino sólo de algo diferente (héteron)" (257 b).

Ser y no ser no son más conceptos contradictorios, sino diferentes. ¿Podemos decir entonces que Parménides ha sido superado? En un aspecto, del cual Parménides no se había ocupado, sí; pero en el ámbito que realmente le interesó, no; al contrario: fue confirmado. Veamos por qué.

La negación, como vimos en la primera parte de este trabajo, es una noción peligrosa, y Platón es consciente del riesgo que corre. Para justificar la solución a la que llegó, fiel a su filosofía, Platón postula una nueva Forma que garantiza que se pueda afirmar que algo es diferente de otra cosa: la Forma de Lo Otro, Lo Diferente (tò héteron). Así como Lo Bello comunica belleza, Lo Diferente comunica diferencia, alteridad. Esta Forma es de participación universal, ya que toda cosa (individual, inteligible, idea, etc.) es diferente de otra; no hay excepciones. Pero para que una cosa pueda ser diferente de otra, debe tener su propia identidad, lo cual lleva a Platón a postular una nueva Forma, paralela a la de Lo Otro: Lo mismo, Lo idéntico (tautón). También la Identidad es una forma de participación universal, ya que todo es idéntico a sí mismo.

Las Formas de Identidad y de Diferencia caracterizan lo que podríamos denominar la esencia de cada cosa, ya que la definen, y la participación de cada cosa en la Forma de Ser (también, como vimos, de participación universal) garantiza ya cierto tipo de existencia. Y, para justificar la búsqueda de los filósofos anteriores que habían concebido que la realidad (ousía) consistía en entidades o sometidas al cambio o inalterables (según la escuela), Platón postula dos nuevas Formas, Reposo y Movimiento (o cambio), que existen porque participan de la Forma de Ser. A diferencia de Identidad y de Diferencia, estas nuevas Formas no son de participación universal, pero dividen la manera de ser de las entidades en forma absoluta. Estas cinco Formas (Ser, Identidad, Diferencia, Reposo, Movimiento) son consideradas "principales".

Volvamos a nuestro tema: la negación como diferencia. Como vimos, Platón llegó a esta solución para justificar la noción de no ser, que no es la contraria del ser. Como toda noción en Platón (como la belleza, la justicia, lo grande), el no-ser tiene como garantía una Forma, la Diferencia, que, como vimos, tiene como contrapartida la Identidad, así 
como el Reposo tiene al Movimiento. O sea que la Forma de la Diferencia justifica al no ser... pero sólo en tanto diferencia. Y ocurre que "diferencia" -es Platón quien lo dice- es una noción relativa. Nada es diferente en sí, nada es otro en sí; todo lo que es diferente es "diferente de...", u "otro que...". El no ser cuya garantía es la Forma de Lo Otro es un no ser relativo, no es autónomo.

Ahora bien: ċrespecto de qué es relativo el no ser relativo? Es relativo respecto de la noción que se le opone; basta retirarle el "no" que la precede. Imaginemos algo blanco. Para garantizar esta noción, Platón recurre a la Forma del Ser, que le da existencia, y a la Forma de Lo Mismo, que asegura su identidad (que justifica que lo blanco es blanco). Pero lo blanco tiene un no-ser, que es sólo suyo, y que es su "otro": lo no-blanco. O sea que la Forma de Lo Otro permite que algo, que está ya caracterizado por su identidad y que existe, pueda estar opuesto a otra realidad, lo no-blanco, sin que por ello lo no-blanco deje de existir. Enfrentado a todo cuanto es blanco, lo no-blanco existe. Está en la región de Lo Otro, desde la cual se encuentra enfrentado antitéticamente a lo blanco. Ergo, todo cuanto es no-blanco, es también real. Lo no-blanco es el no-ser relativo a lo blanco; es la parte de la Diferencia que le corresponde, que sólo existe si existe algo blanco. Si lo blanco no existiera, tampoco existiría lo no-blanco. Como en Parménides, la negación es secundaria respecto de la afirmación...

Es en este momento en que Platón cae en la trampa tendida por la negación. La negación del ser lo obliga a remitir el no-ser a la diferencia, que es el único no-ser concebible, pero que es relativo. Si es así, puede decirse que el no ser descubierto por Platón queda reducido al ámbito de la predicación. Y un lógos falso, al decir "lo que no es", dice sólo algo "diferente de lo que es". El no ser que descubre Platón es un "no ser... X". El peso abrumador de la negación parmenídea se impone: no existe un no-ser absoluto, que sería la No-Existencia o la Nada, que, según su descubrimiento, tendría que ser lo Otro del Ser. La Forma de Ser, que él descubre, "da" ser a toda la realidad, en definitiva, como en Parménides. Y no hay una sexta Forma, que sería la Forma de no Ser.

Platón es consciente del problema. Después de haber descubierto un no-ser que es sólo relativo, en una frase que es una verdadera confesión, escribe (258 e):

Que no se diga, entonces, que, cuando nos atrevemos a afirmar que el no-ser existe, hacemos alusión al contrario del ser. En efecto: respecto del contrario del ser hace ya tiempo que le hemos dado la despedida, exista o no, sea captable racionalmente o sea completamente irracional.

Platón no sólo no refutó a Parménides, sino que lo mejoró. El hecho de ser necesario y absoluto deviene ahora, gracias a Platón, una Forma que está presente en todo lo que es. Parménides, desde la tumba, le hubiese agradecido la colaboración. 


\section{Bibliografía citada}

BENVENISTE, E. (1966), Catégories de pensée et catégories de langue. En Problèmes de linguistique générale, I, Gallimard.

BERGSON, H. (1907). L'évolution créatrice. Alcan.

CORDERO, N. L. (2005). Siendo, se es. La tesis de Parménides, Buenos Aires, Biblos.

CORNFORD, F. M. (1983). La teoría platónica del conocimiento. Paidós.

FÜLLEBORN, G. G. (1795). Fragmente des Parmenides. Friedrich Fromann.

HÖFFDING, H. (1901) La base psychologique des jugements logiques. La Révue Philosophique, 26.

KRUG, W. T. (1806). System der theoretischen Philosophie, I: Denklehre oder Logik" Königsberg.

REINHARDT, K. (1916). Parmenides und die Geschichte der griechische Philosophie. V. Klostermann.

SARTRE, J. P. (1943). L'être et le néant. Gallimard.

SIGWART, C. v. (1914). Logik. Tübingen

\section{Notas}

${ }^{1}$ Nos resignamos a utilizar, con las reservas ya señaladas, el término "fragmento".

${ }^{2}$ Los dos caminos permiten pensar, "eisi noêssai". "Noêsai" es infinitivo aoristo con valor de finalidad o de instrumento. En 99\% de las traducciones del Poema se lee que los caminos son "pensables", como si el término griego hubiese sido el adjetivo verbal noêtaí. La traducción es absurda, porque el contenido de uno de los caminos no es "pensable". Este camino negativo encamina al pensamiento y lo conduce a un callejón sin salida, o, peor aún, a un círculo vicioso.

3 Éste es uno de los casos en los cuales no caben dudas de que el "fr. 6" ha de haber figurado, en el origina, y ya no sólo en las reconstrucciones actuales del Poema, después del fr. 2.

${ }^{4}$ Por esta razón la diferencia entre ambas tesis no obedece al esquema A o B, sino A o no-A.

${ }^{5}$ SARTRE (1943, p. 51).

${ }^{6}$ HÖFFDING (1901, p. 374).

${ }^{7}$ KRUG (1806, p. 118).

${ }^{8}$ SIGWART (1924, p. 155).

${ }^{9}$ BeRgson (1907, p. 309).

${ }^{10}$ Expresión utilizada por BENVENISTE (1966).

${ }^{11}$ CORNFORD (1983, p. 192).

${ }^{12}$ Acerca de la preferencia por el texto transmitido por Proclo (eph' hội) en vez de la versión, generalmente aceptada, propuesta por Simplicio, en hội (que constituye un contrasentido: cंcómo 
el pensamiento podría estar expresado en el ser? Es más bien a la inversa), ver CORDERO (2005, p. 102 ss.).

${ }^{13}$ Platón ve con claridad que la filosofía de Parménides no deja lugar a la existencia real de las dóxai (opiniones) y por esa razón esta noción siempre recibe, en el Poema, epítetos que la devalúan. Curiosamente, la inmensa mayoría de los estudiosos consideran que cuanto Parménides dice sobre las dóxai representa una parte de su propia filosofía. El iniciador de este desatino fue FülLEBORN (1795); REINHARDT (1916) lo justificó a su manera y en el siglo XX lo popularizó la prosa poética de HEIDEGGER.

${ }^{14}$ Recordar las palabras que Platón, en el Timeo, pone en boca de un anciano sacerdote egipcio que dialoga con Solón: “iSolón, Solón! Ustedes, los griegos, serán siempre niños” (22b). 